\title{
SOIL STRUCTURE INTERACTION EFFECT ON DYNAMIC BEHAVIOR OF 3D BUILDING FRAMES WITH RAFT FOOTING
}

\author{
Kuladeepu M N ${ }^{1}$, G Narayana $^{2}$, B K Narendra ${ }^{3}$ \\ ${ }^{1}$ Post Graduate Student, Department of Civil Engineering, SJCIT, Karnataka, India \\ ${ }^{2}$ Professor and HOD, Department of civil engineering, SJCIT, Karnataka, India \\ ${ }^{3}$ Principal, Department of civil engineering, BGSIT, Karnataka, India
}

\begin{abstract}
The soil flexibility effect is generally not considered in seismic design of building frames and the design is done based on results of dynamic analysis taking fixed base condition. Flexibility effect of soil causes lengthening of lateral natural period due to overall reduction in lateral stiffness of the structure. Such lengthening lateral natural period (T) may considerably vary the seismic response of building frames resting on raft foundation. Hence it is necessary to unite the flexibility of soil on which the foundation rests during analysis such study being termed as soil structure interaction (SSI).

In the present study the dynamic behavior of building frames over raft footing under seismic forces uniting soil structure interaction is considered. The analysis is carried out using FEM software SAP2000*Ver14. For the interaction analysis of space frame, foundation and soil are considered as parts of a single compatible unit and soil is idealized using the soil models for analysis. The soil system below a raft footing is replaced by providing a true soil model (continuum model). In continuum model, soil is considered as homogeneous, isotropic, elastic of half space for which dynamic shear modulus and Poisson's ratio are the inputs.
\end{abstract}

Influence of number of parameters such as number of storey's, soil types and height ratio for seismic zone-V is considered in present study. Building responses are considered for bare frame with and without accounting for soil flexibility. The responses in terms of lateral natural period and seismic base shear, lateral displacement (story drift), with and without soil flexibility is compared to evaluate the contribution of soil flexibility on building frames.

Keywords: soil structure interaction, natural period, base shear, max. lateral displacement and raft footing etc...

\section{INTRODUCTION}

Any structure subjected to seismic force during an earthquake, the waves that arrive produce motions in the structure itself. Motions depend on the structures vibrational characteristics and the structural layout or building. For the structure to response to the motion, it needs to overcome its own inertia, which result in an interaction between the structure and the soil. Such an interdependent behavior between soil and structure regulating the overall response is referred as interaction behavior in the present context. It is common practice that we consider the analysis of structure and foundation separately. Based on the assumption that the base of structure is fixed ( i.e., assumption made that the base of the foundations transfer the load by direct bearing on solid rocky stratum) load distributing within the building frames are calculated. There is no doubt that, this assumption is commonly applicable if the superstructure is much more flexible than the underlying soil stratum upon which the foundation rest.

If the reverse is true i.e., assuming that the structure is more stiffer than the soil medium, then the response of structure can be significantly exercised by the flexibility of soil. By the analysis of structure with fixed base condition proves to be lower estimation of certain response quantities as highlighted in few earlier researches.
The overall stiffness of the structural systems may be decreased due to soil flexibility and hence may increase in natural period of system. Such increase in lateral natural period may considerably varies the response of building frames under the earthquake forces. For this, the present study has been carried out for dynamic response of building frames resting over raft foundation considering soil flexibility with that of a fixed base under the influence of various parameters.

The soil considered is sandy clay and is idealized as continuum model. In the present study earthquake load is applied individually along horizontal $\mathrm{X}$ and $\mathrm{Y}$ directions..

\section{MODELING AND ANALYSIS METHOD}

The building superstructure is romanticized as 3 dimensional space frame comprising of columns in every story and beams and slabs at every floor (fig. 1). In every story two noded line components with six degrees of opportunity at every node speak to beams and columns. At every floor level, adaptable floor diaphragm for section is discretized and is modeled as thin shells with four noded plate components with six degrees of opportunity at every node ( three interpretations and three revolutions in their separate direction bearings). 
Finite element idealization of raft foundation is carried out in the same way as that of the soil i.e., utilizing eight noded SOLID components for continuum model (fig. 2) having three degrees of freedom of interpretation in the particular direction bearings at every node. The soil considered is sandy clay and is romanticized as continuum model. In the present study earthquake load is connected exclusively along horizontal level $\mathrm{X}$ and $\mathrm{Y}$ directions. Dynamic investigation (Response Spectrum Method) is done according to IS 1893-2002 (section 1) for structure modeled with fixed base (Non Interaction Analysis) and flexible base (Interaction Analysis) utilizing SAP2000 V14

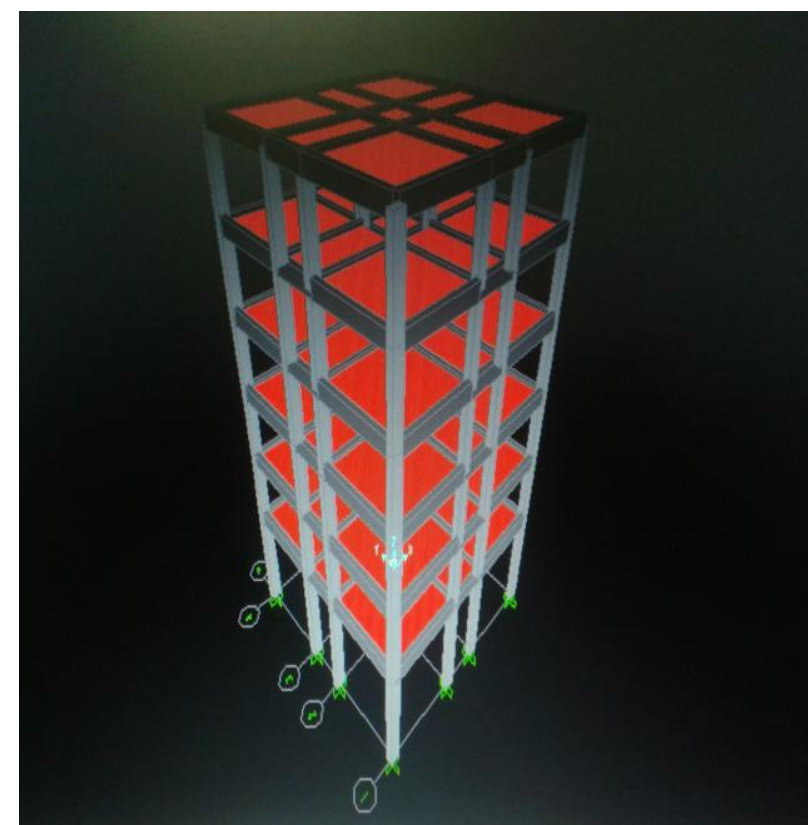

Fig. 1: Idealization of beams, columns and slab of 3X3bay 6 storey building frame with fixed base.

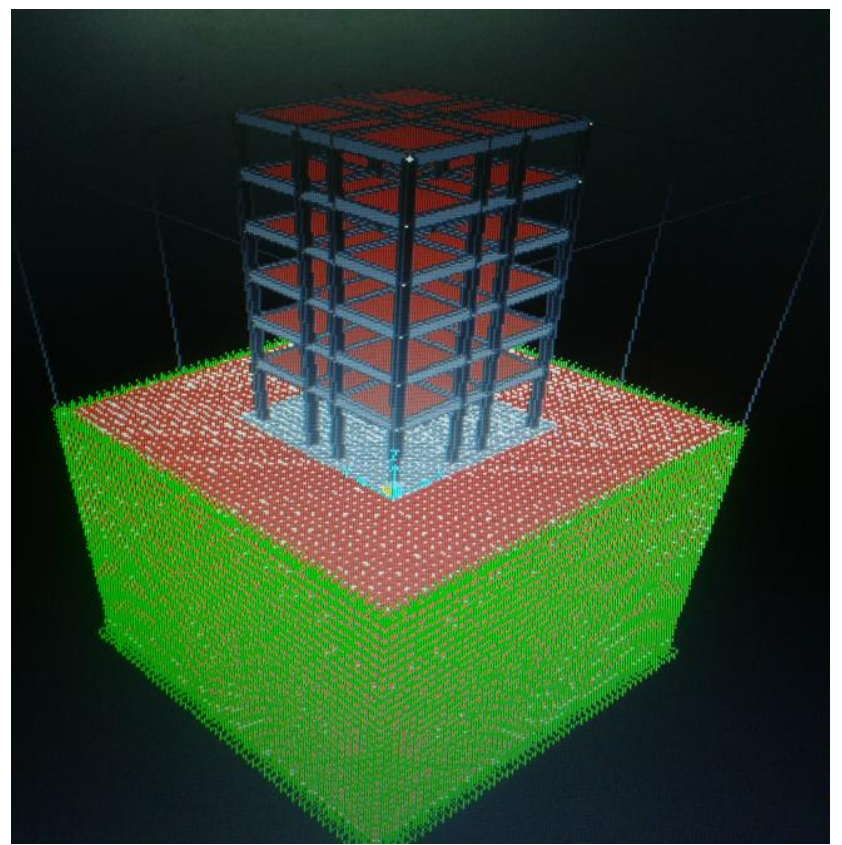

Fig. 2: Idealization of continuum soil model of $3 \mathrm{X} 3$ bay 6storey building frame.

\section{SCOPE OF THE PRESENT STUDY}

a) Description of Building Model with Raft Foundation For the present study, Three bay Three bay - six, eight and ten storied reinforced concrete moment resisting frame building structures are picked (without considering stiffness (solidness) of infill). The story tallness of base story is $4.5 \mathrm{~m}$ (termed Ratio of Base story to higher stories $\mathrm{Hr}=1.5$ from this time forward) and is kept at $3 \mathrm{~m}$ for the various stories in the model. No parapets on the rooftop story yet all-round block infill brick work divider ( $230 \mathrm{~mm}$ thick) in the middle stories, is considered in the structure. The building is demonstrated as exposed casing; however masses of the dividers are incorporated. To study the impact of soil flexibility, continuum model is utilized.

b) Input design data for building models with raft foundations

The material properties considered are:

Young's modulus of M25 concrete, E=25×106 kN $/ \mathrm{m}^{2}$, Density of Reinforced Concrete $=25 \mathrm{kN} / \mathrm{m}^{3}$, Density of brick masonry $=20 \mathrm{kN} / \mathrm{m}^{3}$, Dead load intensities like Floor finishes $=1.0 \mathrm{kN} / \mathrm{m}^{2}$, Roof finishes $=2.0 \mathrm{kN} / \mathrm{m}^{2}$, Live load intensities on Roof $=1.5 \mathrm{kN} / \mathrm{m}^{2}$ and on Floor $=3.0 \mathrm{kN} / \mathrm{m}^{2}$,

Member properties taken are:

Thickness of Slab $=150 \mathrm{~mm}$, Column size $=350$ $\mathrm{mm} \times 500 \mathrm{~mm}$, Beam size $=250 \mathrm{~mm} \times 600 \mathrm{~mm}$, Thickness of wall $=230 \mathrm{~mm}$, Earthquake live load on slab as per clause 7.3.1 and 7.3.2 of IS:1893-2002 (Part 1) is calculated as: $\quad$ Roof $=0.25 \times 1.5=0.375 \quad \mathrm{KN} / \mathrm{m}^{2}$, Floor $=0.25 \times 3.0=0.75 \mathrm{KN} / \mathrm{m}^{2}$.

Seismic data:

Seismic Zone V, Response spectra=As per 1893(part 1)2002, Importance factor $=1$, Response reduction factor $=5$. The foundation dimensions were designed for gravity load and all its load combinations, using STAAD pro V8i software package. The raft with plan dimensions $12 \mathrm{~m} \times 12 \mathrm{~m}$ is adopted for all building models with the thickness of raft being $0.75 \mathrm{~m}, 0.8 \mathrm{~m}$ and $0.9 \mathrm{~m}$ for Six storey, Eight storey and Ten storey building frames respectively.

c) Soil Parameters Considered

The type of soil considered is sandy clay (Bowles, 1996) classified as soft, medium and stiff soil based on Dynamic shear modulus $(G)$.

Properties of soil types considered in this study are Stiff (Type-I with $\mu=0.2$ and $\mathrm{G}=30000 \mathrm{KN} / \mathrm{m}^{2}$ ); Medium (Type-II with $\mu=0.25$ and $\mathrm{G}=20000 \mathrm{KN} / \mathrm{m}^{2}$ ) and Soft (Type-III with $-\mu=0.3$ and $\mathrm{G}=10000 \mathrm{KN} / \mathrm{m}^{2}$ ). 


\section{RESULTS AND DISCUSSION}

\subsection{Lateral Natural Period}

Variety of Fundamental regular period Tn with shear modulus of three types of soil for Zone $\mathrm{V}$ are plotted for the three types of soil models and frame type of 3bay 6 storey, 8 story and 10 stories with $\mathrm{Sr}=1$ and $\mathrm{Hr}=1.5$ in fig 3.a \& 3.b. For any frame type and soil model considered, there is comparable variety in Tn with shear modulus of soil, i.e. it marginally diminishes with expansion in shear modulus.

In correlation to NIA, Tn generously increments in the interaction analysis as the structure foundation soil system is rendered flexible. The level of variety relies on upon kind of soil model and soil type. It is obvious that the natural period is moderately higher as number of stories is expanded. Tn of the considerable number of models are more noteworthy than the estimations of NIA in all types of soils. Between the soil models, continuum is observed to predict maximum variation with respect to NIA.

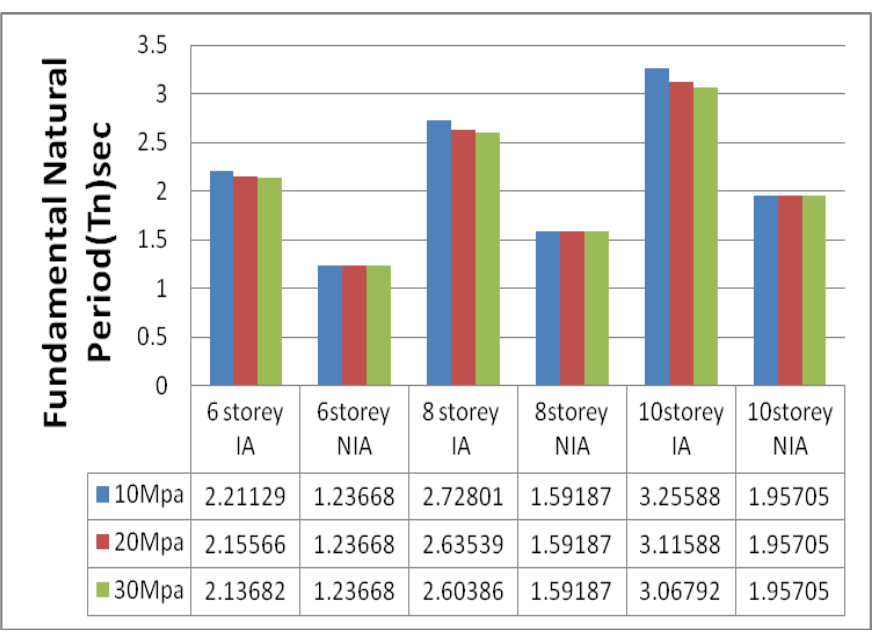

Fig 3.a

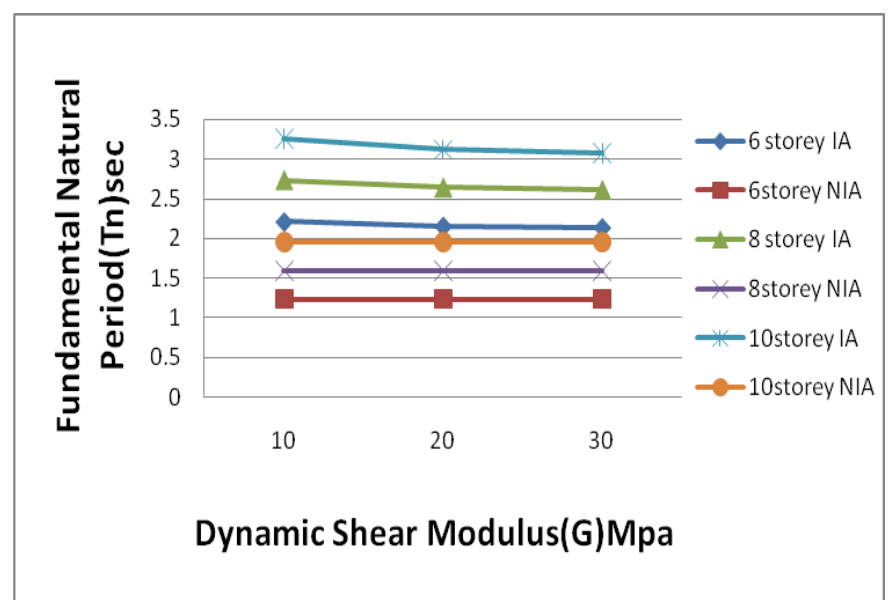

Fig 3.b Represents the variation of Fundamental Natural Period(Tn) vs dynamic shear modulus $(G)$

\subsection{Change in Base Shear}

Beneath figures (Fig 4.a \& 4.b) demonstrates the resulting base shear (VB) for different number of stories of the frame and types of soil. It is show there is increment in the base shear in light of expansion in number of stories. Likewise seen that decrease in base shear values from soil type soft to hard which is more agent for 10 story than six and eight storied structures.

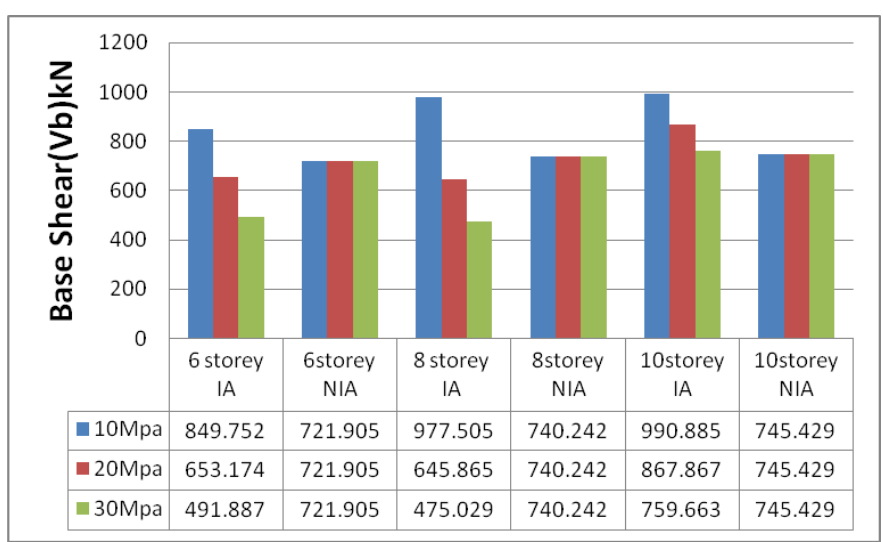

Fig 4.a

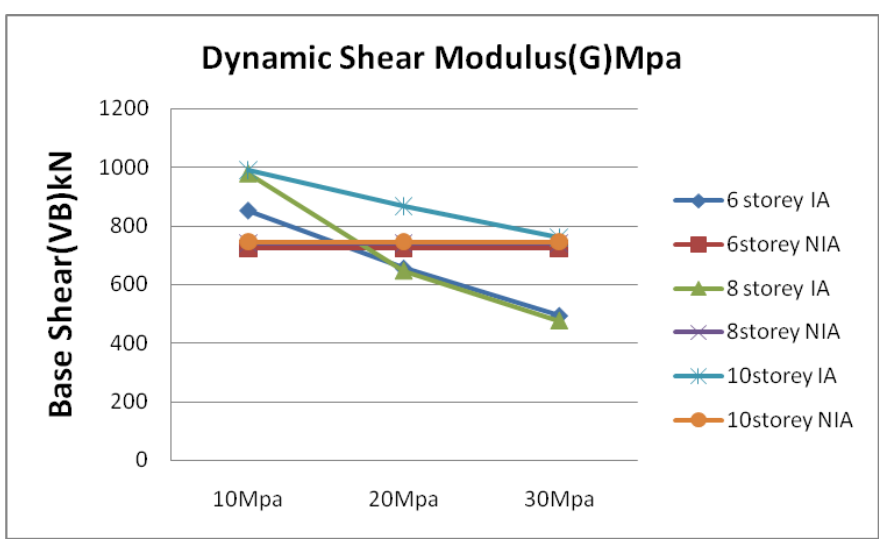

Fig 4.b Variation of Base shear with Shear Modulus of Soil

\subsection{Maximum Lateral Displacement}

The lateral displacement $(\Delta)$ values in the chart are those are maximum values out of different modes of deformation. Comparison to Non interaction analysis, the maximum lateral displacement $(\Delta)$ substantially increases in the interaction analysis Fig.5.a and Fig.5.b.

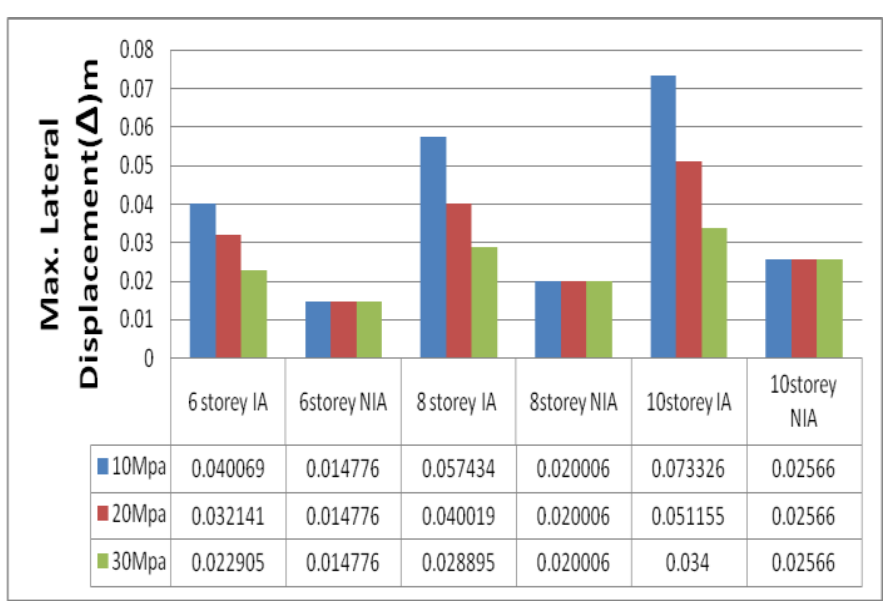

Fig 5.a 


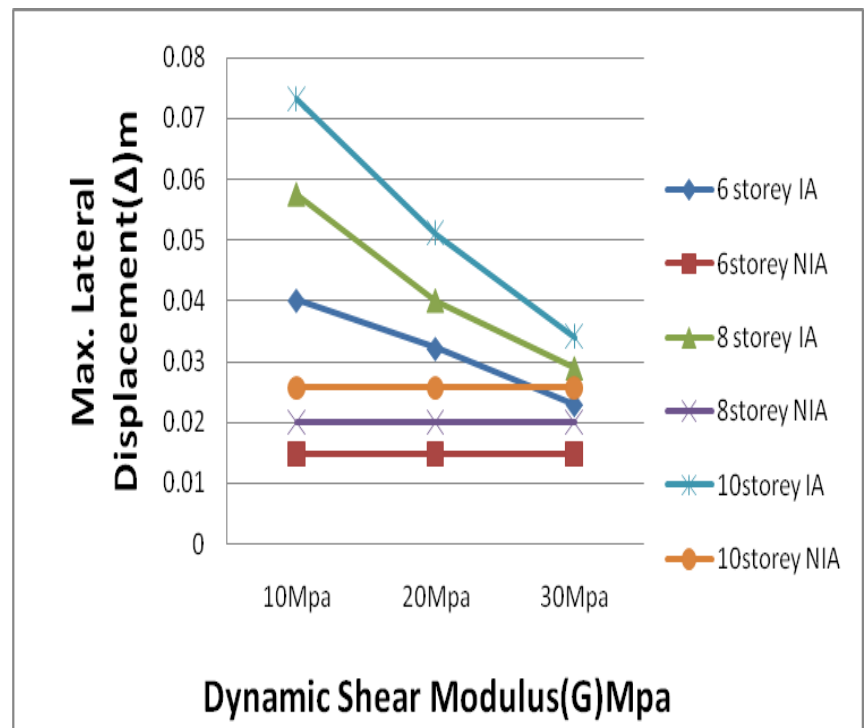

Fig 5.b Variation of Max. Lateral Displacement with Shear Modulus of Soil

\section{CONCLUSION}

The study leads to the following broad conclusions:

1) Fundamental natural period

The fundamental natural period of a specific structure considering interaction is more than that of noninteraction investigation furthermore it increments as the shear modulus of the soil declines. With expansion in number of stories fundamental natural period increments.

2) Base shear

Base shear values for interaction case is more than that of non-interaction case, as the shear modulus of the soil abatements base shear increments. With expansion in number of stories base shear increments.

3) Maximum lateral displacement

For the increment in shear modulus and number of stories the maximum lateral displacement of the structural element discovered to be expanded. The estimations of maximum lateral displacement resulting from a fixed base analysis are impressively improved when interaction analysis of the system is considered.

\section{ACKNOWLEDGEMENTS}

The satisfaction and euphoria that accompany the successful completion of any task would be but incomplete without the mention of the people who made it possible, whose constant guidance and encouragement crowned our efforts with success.

We consider it a privilege to express our gratitude and respect to all those who guided us in the completion of this report.
I express my deep sense of sincere gratitude to his holy soul Parama Poojya Jagadguru Padma Bhushan Sri Sri Sri Dr. BALAGANGADHARANATHA MAHASWAMIJI, for his Blessings.

I Also express my deep senseof sincere gratitude to Parama Poojya Jagadguru Sri Sri Sri NIRMALANANDANATHA MAHASWAMIJI, President, Adichichungiri Mahasamsthana Math.

I would like to express my heartfelt gratitude and sincere thanks to Dr. MUNIKENCHE GOWDA T, principal, SJCIT, CHICKBALLAPUR for providing us the facilities. I extremely thankful to my internal guide Dr. G NARAYANA, Professor \& HOD, Dept of Civil Engineering, SJCIT for his valuable guidance.

I extremely thankful to my external guide Dr. B K NARENDRA, Principal, BGSIT for his valuable guidance. Last but not the least we extend our sincere thanks to our beloved PARENTS and MY FRIENDS for their continuous support, inspiration and encouragement.

\section{REFERENCES}

[1] Bowles J.E, 1996. "Foundation Analysis and Design", $5^{\text {th }}$ Edition,McGraw-Hill International Editions, Civil Engineering Series, New York,

[2] Chandrashekar. A, Jayalakshmi B.R, Katta Venkataramana, 2005. "Dynamic soil-structure interaction effects on multi storied RCC frames" Proceedings of International Conference on Advance to structural dynamics and its application7-9 December, ICASDA, 454-467.

[3] IS: 1893(part 1): 2002, "Criteria for Earthquake Resistant Design of Structures", part 1-General provisions and buildings, fifth revision, Bureau of Indian Standards, New Delhi, India.

[4] IS: 456-2000, "Code of Practice for Plain and Reinforced Concrete", Bureau of Indian Standards, New Delhi, India.

[5] Jisha S.V, Jayalekshmi B.R and Shivashankar R, "Contact pressure distribution under raft foundation of tall reinforced concrete industrial chimneys due to dynamic soil structure interaction", ISET golden jubilee symposium, Paper No. C003, 2012.

[6] PhD Thesis by Dr. G Narayana, "Effect of foundation flexibility on seismic response of structures- An analytical study ", Bangalore University 2012.

\section{BIOGRAPHIES}



Mr KULADEEPU M N, Pursuing Final year M-Tech in SJC Institute of Technology Chickbalapur. Completed My Under Graduation In SJCIT Chickbalapur Under VTU. marepalli.kuladeepu@gmail.com 


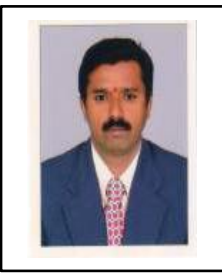

Dr. NARYANA G, Professor and HOD, Department of Civil Engineering SJC Institute of Technology chickballapur. He had very wide experience of Teaching and Research in the Field of Structural Engineering, also a Structure design Consultant for many Projects.

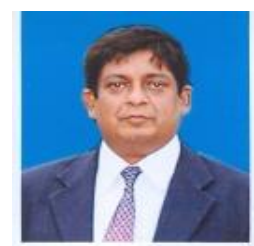

Dr B K NARENDRA, Principal, BGS Institute of Technology. He had wide experience of teaching, administration and research in the field of structural engineering. 